\title{
Analisis Quality of Service (QOS) Jaringan Internet Fakultas Teknik Universitas Muhammadiyah Makassar
}

\author{
Akbar $^{* 1}$, Saiful ${ }^{2}$ \\ ${ }^{1,2}$ Program Studi Teknik Elektro Fakultas Teknik Unismuh Makassar \\ e-mail: akbarteknik93@gmail.com*
}

\begin{abstract}
Analysis Quality of Service (QoS) Internet Network Faculty of Engineering, University of Muhammadiyah Makassar guided by Zahir Zainuddin and Rahmania. QoS parameters were observed or measured is Bandwidth, Delay, Packet Loss and throughput. This research was conducted at the Faculty of Engineering, University of Muhammadiyah Makassar, this study aims to measure, analyze and determine Kualitias Internet Network Engineering Faculty of Muhammadiyah University Makassar. To measure Delay, Packet lost and throughput using software Axence NetTools 4.0 Pro. The results of measurements of parameters of Quality of Service (QoS) Internet network is measured is the bandwidth available on Thursday, Friday and Saturday $=10240$ Kbps. Delay highest in the can on Thursday $=74.66 \mathrm{~ms}$, while the lowest in the delay may be on Saturdays = $62 \mathrm{~ms}$. Packet loss is the highest obtained on Thursday = $5.33 \%$, while the lowest in the lost packet can be on Saturdays $=0.33 \%$. The highest throughput in the can on Saturdays = 357106 bps, while the lowest in the throughput can be on Thursday $=278039$ Bps. Based on the data delay and packet loss above, Internet Network Quality Faculty of Engineering, University of Muhammadiyah Makassar categorized as very good.
\end{abstract}

Keyword: Internet; Bandwidth; Delay; Packet Loss; Troughput

\section{Abstrak}

Analisis Quality of Service (QoS) Jaringan internet Fakultas Teknik Universitas Muhammadiyah Makassar dibimbing oleh Zahir Zainuddin dan Rahmania. Parameter QoS yang diteliti atau diukur adalah Bandwidth, Delay, Packet Loss dan Troughput. Penelitian ini dilakukan di Fakultas Teknik Universitas Muhammadiyah Makassar, penelitian ini bertujuan Untuk mengukur, menganalisis dan mengetahui Kualitias Jaringan Internet di Fakultas Teknik Universitas Muhammadiyah Makassar. Untuk mengukur Delay, Packet lost dan Troughput menggunakan software Axence NetTools 4.0 Pro. Hasil pengukuran parameter Quality of Service (QoS) jaringan internet yang di ukur adalah Bandwidth tersedia pada hari kamis, jumat dan sabtu $=10240 \mathrm{Kbps}$. Delay paling tinggi di dapat pada hari kamis $=74,66 \mathrm{~ms}$, sedangkan delay paling rendah di dapat pada hari sabtu $=62 \mathrm{~ms}$. Packet loss paling tinggi didapat pada hari kamis $=5,33 \%$, sedangkan packet lost paling rendah di dapat pada hari sabtu $=0,33 \%$. Troughput tertinggi di dapat pada hari sabtu $=357106 \mathrm{Bps}$, sedangkan troughput terendah di dapat pada hari kamis $=278039$ Bps. Berdasarkan data delay dan Packet loss diatas, Kualitas Jaringan Internet Fakultas Teknik Universitas Muhammadiyah Makassar dikategorikan sangat bagus.

Kata kunci: Internet, Bandwidth, Delay, Packet Loss, Troughput

\section{Pendahuluan}

Perkembangan teknologi informasi dan teknologi komunikasi telah sukses melahirkan teknologi baru yang kita sebut dengan teknologi internet. Semenjak kelahirannya teknologi internet berkembang dengan pesat dan sudah dipakai di seluruh dunia. Dengan teknologi internet, manusia telah berhasil menghubungkan wilayah-wilayah dunia ini menjadi satu dalam jaringan komputer yang sangat besar, sehingga seakan-akan tidak ada batas-batas wilayah yang satu dengan yang lain. Internet adalah kumpulan dari beberapa komputer, yang bahkan dapat mencapai jutaan komputer di seluruh dunia yang dapat saling berhubungan serta saling terkoneksi satu sama lainnya. Agar komputer dapat salin terkoneksi satu sama lain, maka diperlukan media untuk saling menghubungkan antar komputer. Media yang digunakan itu bisa menggunakan kabel/serat optic, satelit atau melalui sambungan telepon [1]. 


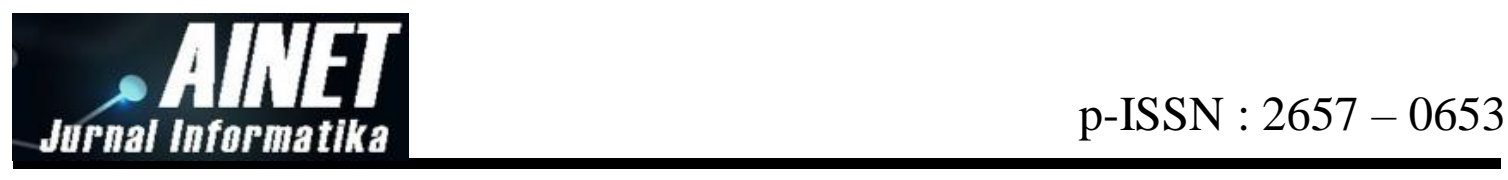

Hadirnya teknologi internet disambut gembira oleh masyarakat dunia karena teknologi ini dirasakan sangat menunjang pada efektifitas dan efisiensi kerja bagi para pemakai. Hal ini dirasakan oleh para pemakai baik dari pemakai yang sifatnya pribadi sampai dengan pemakai pada kalangan korporasi. Dengan kata lain saat ini jaringan internet telah mampu memberikan kontribusi yang besar bagi kehidupan masyarakat modern.

Pemanfaatan internet saat ini sudah menjadi tren kebutuhan, mulai dari dunia bisnis, pendidikan, hiburan, pemerintahan, dan lain-lain. Dalam dunia pendidikan saat ini penggunaan internet sudah diterapkan mulai dari tingkat dasar sampai ke perguruan tinggi.

Fakultas Teknik Universitas Muhammadiyah Makassar sebagai salah satu instansi yang bergerak dibidang pendidikan yang turut berperan aktif dalam mencerdaskan kehidupan bangsa, memerlukan sarana dan prasarana serta memanfaatkan kemajuan teknologi informasi untuk mencapai hasil yang optimal, misalnya internet. Jaringan internet di Fakultas Teknik Unismuh Makassar dibentuk sebagai sarana untuk mengakses informasiinformasi yang dibutuhkan oleh mahasiswa, dosen, staf fakultas dan masyarakat umum. Untuk sekarang kebutuhan internet di Fakultas Teknik Unismuh Makassar hanya digunakan untuk akses internet dan layanan akademik saja, tetapi para user juga memanfaatkan layanan internet untuk streaming video, video call, dll. Hal ini jelas akan sangat mempengaruhi kecepatan koneksi jaringan internet di Fakultas Teknik Unismuh Makassar. Beranjak dari hal tersebut maka perlu adanya suatu analisis Quality of Service (QoS) untuk mengatasi permasalahan tersebut.

\section{Metode Penelitian}

Metode penelitian yang digunakan dalam kegiatan penelitian ini adalah:

1. Diagnosa (Diagnosing)

Melakukan diagnosa, dimana peneliti melakukan identifikasi masalah pokok yang ada guna menjadi dasar penelitian ini adalah menganalisis pada sistem jaringan local area network (LAN).

2. Tindakan (Action Taking)

Melakukan tindakan, dimana peneliti akan memulai melakukan rencana pengukuran dimana penulis akan menyusun rencana tindakan berupa memulai mengukur Bandwidth, Packet loss, Delay dan Troughput.

3. Evaluasi (Evaluating)

Pada tahap ini penulis melakukan evaluasi hasil dari pengujian performa berdasarkan standar parameter Quality of service (QoS) pada jaringan internet Fakultas Teknik Universitas Muhammadiyah Makassar.

4. Pembelajaran (Learning)

Tahap ini merupakan bagian akhir dimana penulis melakukan review tahap-pertahap penelitian.

\subsection{Analisis Kinerja Jaringan}

Dalam Penelitian ini pengukuran dilakukan menggunakan software Axence NetTools 4.0 Pro. Aplikasi tersebut merupakan aplikasi untuk menguji konektivitas pada sebuah jaringan dengan cara mengirimkan paket data ke server yang dituju.

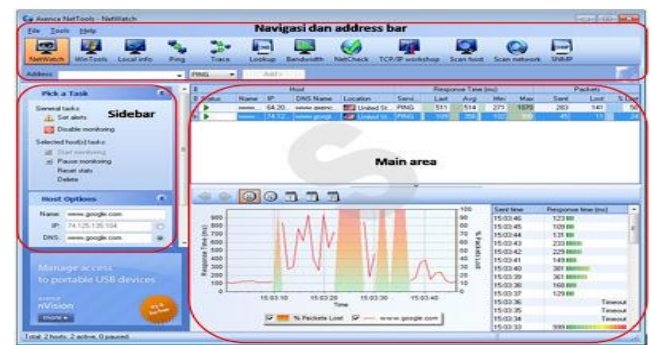

Gambar 1 : Axence netTools 4.0 Pro

Kualitas Layanan (QoS) 

jaringan:

Ada 4 karakteristik untuk melakukan pengukuran kualitas layanan dalam sebuah 1. Packet Loss

Packet Loss merupakan suatu parameter yang menggambarkan kondisi yang menunjukkan jumlah total paket yang hilang, Terjadinya overload trafik didalam jaringan.

Tabel 1. Performansi packet loss

\begin{tabular}{lc}
\multicolumn{2}{c}{ Tabel 1. Performansi packet loss } \\
\hline \multicolumn{2}{c}{ Kategori Packet Loss } \\
\hline Sangat bagus & $0 \%$ \\
Bagus & $3 \%$ \\
Sedang & $15 \%$ \\
Jelek & $25 \%$ \\
\hline & (Sumber : TIPHOM)
\end{tabular}

2. Delay

Delay adalah waktu tunda suatu paket yang dikirim dari satu titik ke titik lain yang menjadi tujuannya.

Tabel 2. Performansi delay

\begin{tabular}{ll}
\multicolumn{2}{c}{ Tabel 2. Performansi delay } \\
\hline \multicolumn{2}{c}{ Kategori Besar Delay } \\
\hline Sangat bagus & $<150 \mathrm{~ms}$ \\
Bagus & $150 \mathrm{~s} / \mathrm{d} 300 \mathrm{~ms}$ \\
Sedang & $300 \mathrm{~s} / \mathrm{d} 450 \mathrm{~ms}$ \\
Jelek & Jelek $>450 \mathrm{~ms}$ \\
\hline & (Sumber: TIPHOM)
\end{tabular}

3. Throughput

Throughput adalah ukuran dari kecepatan dimana data dapat dikirim melewati jaringan dalam bit per second (bps).

Tabel 3. Performansi Troughput

\begin{tabular}{ll}
\hline \multicolumn{2}{c}{ Kategori Throughput } \\
\hline Sangat bagus & $75 \mathrm{~s} / \mathrm{d} 100 \%$ \\
Bagus & $<75 \mathrm{~s} / \mathrm{d} 50 \%$ \\
Sedang & $<50 \mathrm{~s} / \mathrm{d} 25 \%$ \\
Jelek & $<25 \%$ \\
\hline & (Sumber: TIPHOM)
\end{tabular}

\section{Bandwidth}

Bandwidth adalah luas atau lebar cakupan frekuensi yang digunakan oleh sinyal dalam medium transmisi. Bandwidth sering digunakan sebagai suatu sinonim untuk kecepatan transfer data (transfer rate) yaitu jumlah Jenis bandwidth ini biasanya diukur dalam bps (bits per second). Adakalanya juga dinyatakan dalam Bps (bytes per second).

\section{Melakukan Rencana Tindakan \\ Pengukuran Delay} name.

Untuk pengukuran Delay, pilih fitur NetWatch lalu masukkan ip address atau domain 


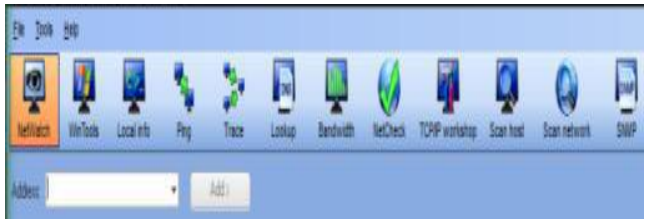

Gambar 2. Memilih Fitur NetWatch

Masukan ip addres (ip addres server) atau domain name yang dituju, tentukan besar paket data yang akan dikirim dan akan didapat statistik seperti berikut ini.

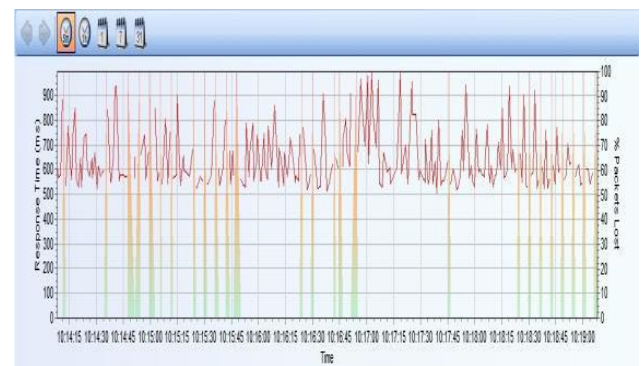

Gambar 3. Statistik hasil Delay

\section{Pengukuran Packet loss}

Cara melakukan pengukuran packet loss menggunakan software Axence Nettools 4.0 Pro sama seperti melakukan pengukuran delay, karena hasil laporan NetWatch juga menunjukan statistik packet loss. Berikut ini contoh statistik laporan.

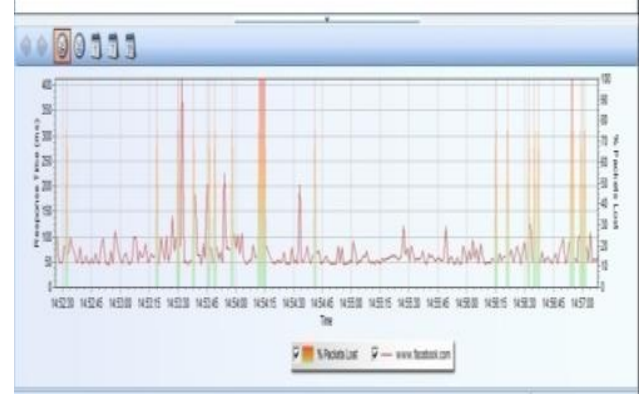

Gambar 4. Statistik hasil Packet Loss

\section{Pengukuran Troughput}

Untuk pengukuran Troughput, Pilih fitur bandwidth lalu masukkan ip address atau domain name.

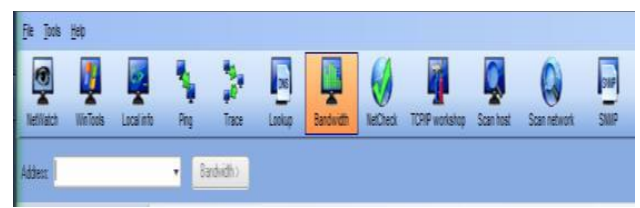

Gambar 5. Memilih fitur Bandwidth

\section{Hasil dan diskusi}

\subsection{Bandwidth}

Unismuh Makassar berlangganan dengan provider internet Indosat M2 Dedicate dengan dengan kapasitas bandwidth 50 Mbps. Dengan bandwidth tersebut kemudian dialokasikan ke masing-masing gedung dengan. Bandwidth yang dialokasikan di gedung lqra Unismuh Makassar pada hari-hari normal adalah $10 \mathrm{Mbps}$. Bandwidth $10 \mathrm{Mbps}$ tersebut di gunakan 4 Fakultas di gedung lqra termasuk di dalamnya adalah Fakultas Teknik. 


\subsection{Delay}

Berdasarkan hasil pengukuran nilai delay terhadap situs yang diukur google.com, facebook.com, dan youtube.com. didapat nilai rata-rata respon time delay minimum dan maksimum dalam millisecond ( $m s$ ) tiap harinya di kategorikan sangat bagus berdasarkan pada standarisasi TIPHON.

\subsection{Packet Loss}

Berdasarkan hasil pengukuran nilai Packet loss terhadap situs yang diukur google.com, facebook.com, dan youtube.com. didapat nilai Packet loss tiap harinya yang di kategorikan bagus untuk hari kamis dan sangat bagus untuk hari jumat dan sabtu berdasarkan standarisasi TIPHON.

\subsection{Troughput}

Berdasarkan hasil pengukuran nilai Troughput, didapat nilai Troughput dalam persentase (\%) yang dikategorikan jelek untuk hari kamis dan jumat dan sedang untuk hari sabtu, berdasarkan standarisasi TIPHON.

Dalam melakukan penelitian beberapa factor yang mempengaruhi pengukuran terhadap parameter QoS adalah sebagai berikut :

1. Redaman, yaitu jatuhnya kuat sinyal karena pertambahan jarak pada media transmisi. tergantung dari bahan yang digunakan. Untuk mengatasi hal ini perlu digunakan repeater sebagai penguat sinyal.

2. Distorsi dan Noise, yaitu fenomena yang disebabkan bervariasinya kecepatan internet atau bandwidth yang diterima client dari ISP (Internet Service Provider) sehingga mengalami variasi delay atau waktu kedatangan paket yang menyebabkann penyempitan bandwidth dan antrian. Untuk mengurangi nilai dalam komunikasi maka dibutuhkan bandwidth transmisi yang memadai dan menjauhkan media transmisi dari medan listrik dan menggunakan kabel yang terisolasi untuk menghindari gangguan (noise).

\section{Kesimpulan}

Adapun kesimpulan dari hasil penelitian Analisis Quality of Service (QoS) Jaringan Internet Fakultas Teknik Universitas Muhammadiyah Makassar adalah Software Axence NetTools 4.0 Pro. digunakan untuk mengukur Delay, Packet lost dan Troughput. Delay paling tinggi di dapat pada hari kamis $=74,66 \mathrm{~ms}$, sedangkan delay paling rendah di dapat pada hari sabtu $=62 \mathrm{~ms}$. Packet lost paling tinggi didapat pada hari kamis $=5,33 \%$, sedangkan packet lost paling rendah di dapat pada hari sabtu $=0,33 \%$. Troughput tertinggi di dapat pada hari sabtu $=$ 357106 Bps, sedangkan troughput terendah di dapat pada hari kamis $=278039$ Bps. Kualitas jaringan internet Fakultas Teknik Unismuh Makassar termasuk stabil.

\section{Referensi}

[1] Hariyawan, M. Yanuar, et al, Study Analisis QOS Pada Jaringan Multimedia MPLS, Teknik Elektronika Telekomunikasi, Politeknik Caltex, Riau, 2011.

[2] Hakim, Lukman Arif Rahman, Analisis dan Implementasi Anlisis Quality of Service (QOS) Pada Jaringan Jardiknas (Jaringan Pendidikan Nasional), Sekolah Tinggi Manajemen Informatika dan Komputer Amikom, Yogyakarta, 2009.

[3] Lipu, Resnu Krestio, Analisis Quality of Service Video Streaming Berbasis Web, Program Studi Teknik Informatika Fakultas Teknologi Informasi Universitas Kristen Setya Wacana, Salatiga, 2013.

[4] Putri, Nurdina Trilisman, et al, Analisis Quality Of Service (QOS) Jaringan Internet pada SMK Negeri 4 Palembang, Universitas Bina Darma, Palembang, 2012.

[5] Romadhon, Pearl Pratama, Analisis Kinerja Jaringan Wireless LAN Menggunakan Metode QOS dan RMA pada PT. Pertamina EP Ebep Ramba (Persero), Fakultas IImu Komputer, Universitas Bina Darma, Palembang, 2014.

[6] Sasmita and Wahyu Patria, Analisis Quality of Service (QoS) Pada jaringan internet (studi kasus : fakultas kedokteran universitas tanjungpura), Prodi Teknik Informatika Fakultas Teknik Universitas Tanjungpura, Tanjungpura.

[7] Setiawan and Eko Budi, Analisa Quality Of Services (QOS) Voice Over Internet Protocol (VOIP) dengan Protocol H.323 dan Session Initial Protocol (SIP), Teknik Informatika UNIKOM, Bandung, 2012. 
[8] Simanjuntak Mei Fenny Wati, et al, Analisis Quality of Service (QoS) Jaringan Telekomunikasi High-Speed Downlink Packet Access (HSDPA) pada Teknologi 3.5G, Program Studi Program Komputer Fakultas Teknik Universitas Diponegoro.

[9] Yanto, Analisis Quality of Service (QoS) Pada jaringan internet (studi kasus: fakultas Teknik universitas tanjungpura), Program Studi Teknik Informatika Jurusan Teknik Elektro Fakultas Teknik Universitas Tanjungpura, Tanjungpura, 2013. 